\title{
Acquired Tracheal Diverticulum as an Unexpected Cause of Endotracheal Tube Cuff Leak
}

\author{
René Agustin Flores-Franco*, Jesús Silva-Alcaraz \\ Departamento de Neumología y Medicina Interna, Hospital General Regional "Dr. Salvador Zubirán Anchondo", \\ Chihuahua, México
}

\begin{abstract}
Introduction: Tracheal diverticulum has been associated with problems during endotracheal intubation but there are no reports concerning air leakage around an endotracheal tube (ETT).

Case report: The case of an elderly woman under mechanical ventilatory support because an exacerbation of chronic obstructive pulmonary disease (COPD) is reported. She presented with an inexplicably air leak around the endotracheal tube not attributed to structural defects. The intra-cuff pressure value was as high as $30 \mathrm{mmHg}$ to prevent an air leakage. Bronchoscopy revealed a tracheal diverticulum at the site ofthe tube cuff that allowed air leakage around it. The problem was overcome by re-intubating the patient with a larger diameter tube and positioning its distal end above the diverticular opening.
\end{abstract}

Discussion: Endotracheal tube air leak is a frequently neglected problem. COPD and other inflammatory conditions are associated with changes in the elastic properties of the airways resulting in tracheomegaly or acquired tracheal diverticulum. Both entities have been linked to problems during intubation or ventilation of patients. However tracheal diverticulum has not been described previously as a cause of air leakage.

Conclusion: Acquired tracheal diverticulum should be recognized as a cause of air leakage in the intubated patient, especially if associated with a normal or elevated intracuff pressure.

Keywords: acquired tracheal diverticulum, tracheomegaly, difficult airway, intubation, endotracheal tube, air leaks, respiratory failure, mechanical ventilation

Received: 09 August 2015 / Accepted: 08 September 2015

\section{INTRODUCTION}

Air leakage around an endotracheal tube (ETT) is a common problem in intensive care units (ICU). Often, this leak is not only caused by a structural defect or inappropriate ETT selection but can also be related to a discrepancy between ETT and tracheal diameters despite adequate cuff inflation, as described in patients who have a dilated trachea [1]. Acquired tracheal diverticulum (ATD) or tracheocele is a rare entity characterized by the localized dilatation of the trachea and is commonly associated with chronic obstructive pulmonary disease (COPD). Incidents related to endotracheal intubation in patients with tracheal diverticulum have been described previously in the literature but none relate to air leakage problems [2-5]. In this report we present a very illustrative example of air leakage attributed to an ATD.

\section{CASE PRESENTATION}

A 78-year-old woman presented with acute exacerbation of chronic obstructive pulmonary disease and severe community-acquired pneumonia. Before admittance she had a five day history of worsened dyspnea, productive cough, and fever. She had a history of smoking forty packets of cigarettes a year, and except for treated hypertension, other medical conditions were unremarkable. On arrival, the physical examination revealed a heart rate of $109 \mathrm{bpm}$, blood pressure of 110/60 mmHg, respiratory rate of twenty eight

\footnotetext{
Correspondence to: René Agustin Flores-Franco, Departamento de Neumología y Medicina Interna, Hospital General Regional "Dr. Salvador Zubirán Anchondo", Av. Colón and Teófilo Borunda 510, Col. Centro. CP 31000 Chihuahua, Chih., México. E-mail: rflores99@prontomail.com

Jesús Silva-Alcaraz: Departamento de Neumología y Medicina Interna, Hospital General Regional "Dr. Salvador Zubirán Anchondo", Av. Colón and Teófilo Borunda 510, Col. Centro. CP 31000 Chihuahua, Chih., México
} 
172 - The Journal of Critical Care Medicine 2015;1(4)

breaths per minute, and pulse oximetry of $84 \%$, measured while she breathed supplemental oxygen via a mask. Chest auscultation evidenced rales and rhonchi on both hemithorax. She was intubated with a $7.5 \mathrm{~mm}$ ETT and started on positive pressure ventilation. The cuff was inflated using the "minimal occluding volume technique". A subsequent chest x-ray showed the full inflated diameter of the cuff greater than the diameter of the trachea (Figure 1). A measuring cuff pressure of $30 \mathrm{mmHg}$ was required to prevent air leakage. At any one time, the plateau pressures were no greater than 30 $\mathrm{cm} \mathrm{H}_{2} \mathrm{O}$.
Available online at: www.jccm.ro

After a few days, it was impossible to wean the patient off the mechanical ventilator so a bronchoscopy was performed which revealed a wide opening pouch on the posterior membrane of the trachea about $1 \mathrm{~cm}$ above the carina, which expanded with each respiratory cycle (Figure 2). During the procedure, the trachea was re-intubated with $8.5 \mathrm{~mm}$ ETT ensuring that its distal end did not reach the diverticulum and the cuff pressure was maintained at $<25 \mathrm{mmHg}$. Despite all supportive measures, unfortunately the patient died one week later due to cardiac arrest.

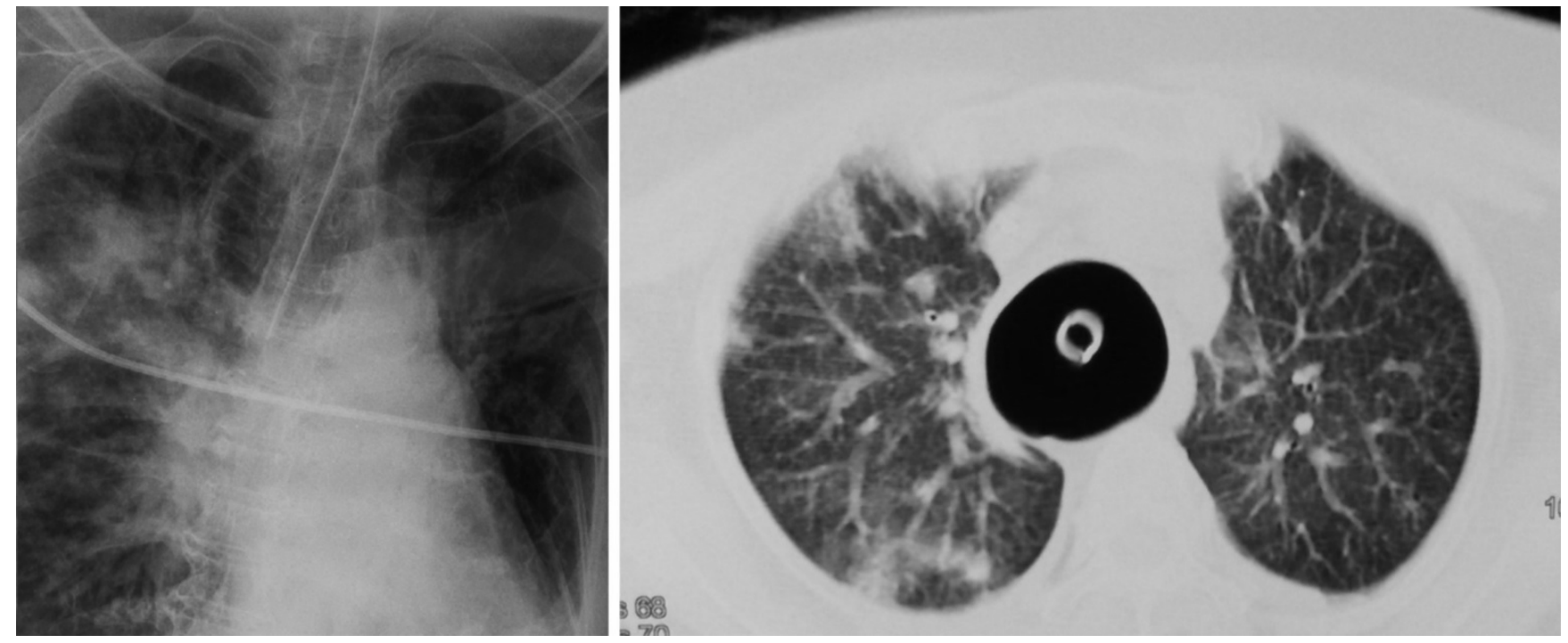

Figure 1. Chest X-ray and chest CT showing both the trachea and cuff with marked dilatation
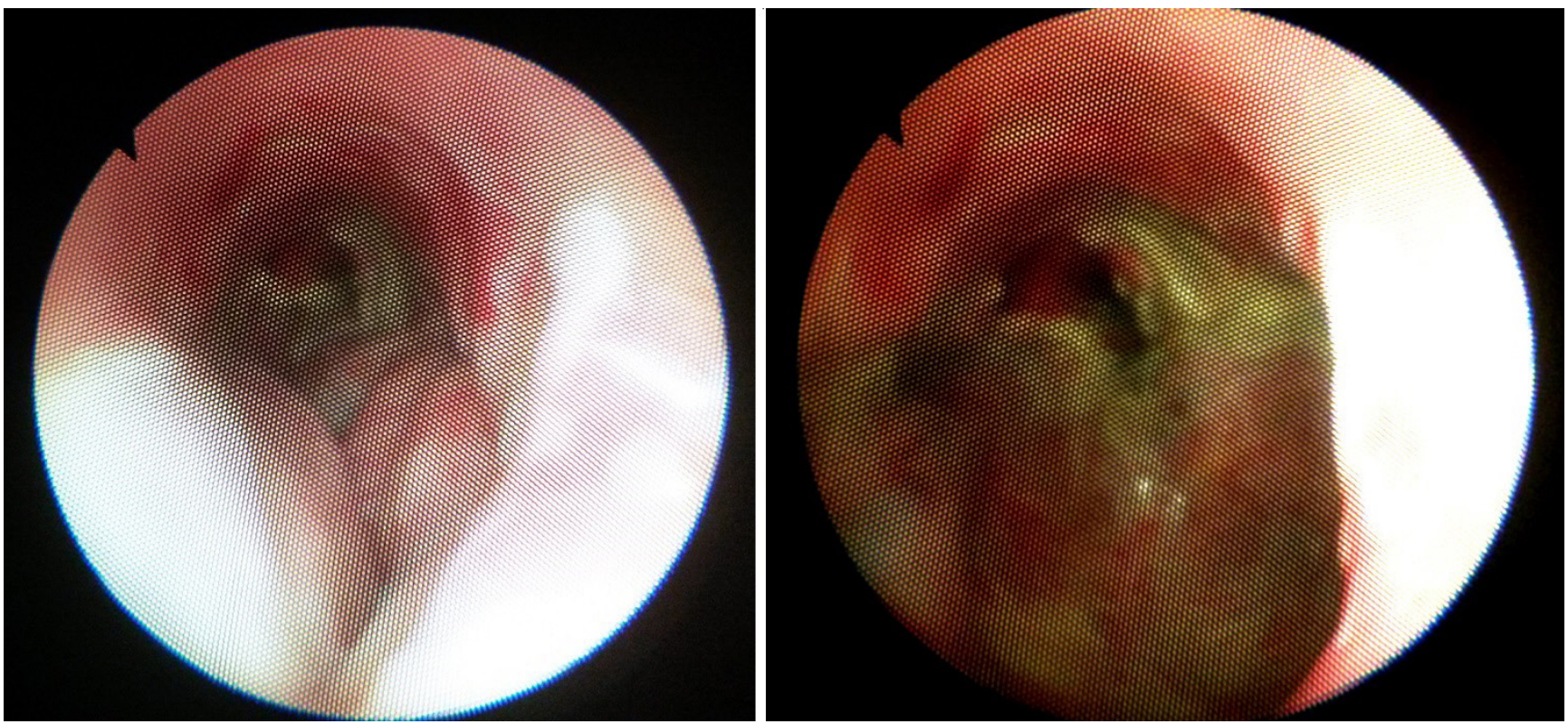

Figure 2. Bronchoscopic images showing the diverticulum sac in the distal trachea during expiratory (left) and inspiratory (right) phases of respiratory cycle and under a pressure support ventilation mode 


\section{DISCUSSION}

According to a recent survey of nurses working in adult ICUs almost $50 \%$ of respondents did not assess the cuff pressure when an an audible leak was detected [6]. An analyze of the results suggested that if there is a need to inflate the cuff to more than $10 \mathrm{ml}$ to avoid a leakage, the practitioner should consider the possibility of the presence of tracheal injury and investigate the cause of the leak [6]. Partial tracheal extubation, inadvert intratracheal placement of the gastric tube, high mean airway pressure and discrepancy between ETT and tracheal diameters, are all causes of air leakage with a normal or elevated intra-cuff pressure [1]. Many possible causes could account for the increases in anteroposterior tracheal diameter but COPD predominates within chronic inflammatory diseases [7]. The chronic damage produced by infectious agents or smoking can weaken the tracheal and bronchial wall. Tracheal diverticulum in adults is a mucosal herniation that occurs in the weak parts of the tracheal wall due to increased intraluminal pressure [8]. In the retrospective analysis of chest CT scans performed in a population of patients with no traumatic pathology, one study demonstrated an incidence of tracheal diverticulum of $2.38 \%$, many of them associated with COPD, especially those with a bronchial localization [8]. Unlike congenital tracheal diverticulum, those acquired are larger and present a more extensive connection with the trachea [2]. This could explain the documented incidents described during intubation of elderly patients with ATD [2-4]. Also, tracheal diverticulum can cause difficult ventilation or pneumo-mediastinum secondary to tracheal perforation during intubation $[4,5]$.

\section{CONCLUSION}

ATD has not been previously described as a cause of air leakage around ETT but similar to tracheomegaly, should be included within the documented causes, produced by a discrepancy between ETT and tracheal diameters, especially when the cuff shares the same localization.

\section{ABBREVIATIONS}

ETT: endotracheal tube

ATD: acquired tracheal diverticulum

COPD: chronic obstructive pulmonary disease

\section{COMPETING INTERESTS}

The authors declare that there are no conflicts of interests regarding the publication of this paper.

\section{REFERENCES}

1. El-Orbany M, Salem MR. Endotracheal tube cuff leaks: causes, consequences, and management. Anesth Analg. 2013;117:42834.

2. Carmona Soto P, Congregado M, Loscertales J. Acquired tracheal diverticulum as the cause of complicated orotracheal intubation. Arch Bronconeumol. 2012;48:64-5.

3. Davies R. Difficult tracheal intubation secondary to a tracheal diverticulum and a 90 degree deviation in the trachea. Anaesthesia. 2000; 55:923-5.

4. Möller GM1, ten Berge EJ, Stassen CM. Tracheocele: a rare cause of difficult endotracheal intubation and subsequent pneumomediastinum. Eur Respir J. 1994;7:1376-7.

5. Afzal M, Chaudhry I. Anesthetic challenges in ventilating patients with tracheal diverticulum: cases report and review of literature. World J Anesthesiol. 2014;3:225-8.

6. Jordan P, van Rooyen D, Venter D. Endotracheal tube cuff pressure management in adult critical care units. S Afr J Crit Care. 2012;28:13-16.

7. Griscom NT, Vawter GF, Stigol LC. Radiologic and pathologic abnormalities of the trachea in older patients with cystic fibrosis. Am J Roentgenol. 1987;148:691-3.

8. Kurt A, Sayit AT, Ipek A, Tatar IG. A multi detector computed tomography survey of tracheal diverticulum. Eurasian J Med. 2013;45:145-8. 